\section{International Scientific Journal Theoretical \& Applied Science}

p-ISSN: 2308-4944 (print) e-ISSN: 2409-0085 (online)

Year: $2018 \quad$ Issue: 02 Volume: 58

Published: $28.02 .2018 \quad$ http://T-Science.org

\section{Ailen Dokturbekovna Adambekova doctor of juridical science Senior Researcher of Academy of Ministry of Interrior Affairs of Kyrgyz Republic}

Mariya Kasimbaevna Sayakova doctor of juridical science, acting professor first vice-rector of Institute of Modern Information Technologies in Education of Kyrgyz Republic

SECTION 32. Jurisprudence.

\title{
SOME QUESTIONS OF THE FORMATION OF THE NORMATIVE LEGAL FRAMEWORK OF NORMATIVE REGULATION OF THE DETENTION OF THE ACCUSED, IN SEARCHING IN THE SEARCH
}

Abstract: The article considers the preconditions for the development of legislation regulating the detention of the accused, who is wanted. The paper describes some aspects of coercion aimed at bringing the persecuted persons to the necessary place.

Key words: detention, accused, search, criminal procedure, charge, rights and freedoms.

Language: Russian

Citation: Adambekova AD, Sayakova MK (2018) SOME QUESTIONS OF THE FORMATION OF THE NORMATIVE LEGAL FRAMEWORK OF NORMATIVE REGULATION OF THE DETENTION OF THE ACCUSED, IN SEARCHING IN THE SEARCH. ISJ Theoretical \& Applied Science, 02 (58): 109-113.

Soi: http://s-o-i.org/1.1/TAS-02-58-23 Doi: crossef https://dx.doi.org/10.15863/TAS.2018.02.58.23

\section{НЕКОТОРЫЕ ВОПРОСЫ СТАНОВЛЕНИЯ НОРМАТИВНО-ПРАВОВОЙ ОСНОВЫ НОРМАТИВНОЙ РЕГЛАМЕНТАЦИИ ЗАДЕРЖАНИЯ ОБВИНЯЕМОГО, НАХОДЯЩЕГОСЯ В РОЗЫСКЕ}

Аннотация: В статье рассмотрен предпосылки развития законодательства регулирующеег задержание обвиняемого, находящегося в розыске. В работе описываются отдельные стороны принуждения, направленного на доставление преследуемых лии в необходимое место.

Ключевые слова: задержание, обвиняемый, розыск, уголовно-прочессуальное право, обвинение, права и свободы.

\section{Introduction}

Нормы уголовно-процессуального права, регулируя отношения между участниками процесса, нацелены на создание оптимальных условий для правильного разрешения, уголовного дела с тем, чтобы защитить права и законные интересы граждан и организаций, потерпевших от преступлений, a также личность от незаконного и необоснованного обвинения, осуждения, ограничения ее прав и свобод.

Одной из гарантий достижения указанной цели является участие обвиняемого в уголовном судопроизводстве. Это побуждает обвиняемого к активным действиям при рассмотрении дела и осуществлению собственной защиты, так как его показания в уголовном процессе играют роль доказательства.

\section{Materials and Methods}

Поскольку обвиняемый не всегда готов в своих интересах подчиниться требованиям следственной или судебной власти о явке, в процесс вводится особая категория мер обеспечения нормального хода производства по делу. По назначению меры можно разделить на две группы:

- препятствующие уклонению обвиняемого от органов предварительного расследования и суда, привлекающие помимо его воли к участию в производстве по уголовному делу (меры пресечения);

- обеспечивающие явку для отдельных действий путем привода, задержания подозреваемого [1, с. 3; 2, с. 323-324].

Данная мера принуждения является новой, о ней не упоминалось в ранее действовавшем УПК РСФСР 1960 г. В связи с этим необходимо выяснить причины, побудившие законодателя 
расширить институт процессуального принуждения.

В поисках решений указанных проблем обратимся к истории развития названного института и отдельных его элементов.

В Древней Руси IX-XI вв. государство не было заинтересовано в ограничении свободы обвиняемого до решения вопроса о его виновности. Эта прерогатива принадлежала частным лицам, именно они были инициаторами применения мер принуждения. Какая-либо правовая процедура задержания и доставления преступника отсутствовало. Обычаи того времени предоставляли лицу и его родовой общине безграничные возможности наказать того, кто посягнул на чужое. Стабилизатором общественных отношений выступала кровная месть (за убийство, увечье, другие «обиды» со стороны членов рода, общины, к которым принадлежал потерпевший). Кровная месть ничем не ограничивалась, наоборот, поощрялась как эффективное средство защиты.

Одним из первых правовых документов Древнерусского государства была «Русская правда», сборник правовых норм [3]. Правовое регулирование было направлено на ограничение вседозволенности, в том числе в отношении преступников, на упорядочение случаев произвольного осуществления кровной мести и установление некоторых правил поведения после задержания преступника. В этот период не существовало расследования в современном понимании, поскольку еще не было специальных органов или лиц, выполнявших сыскные функции. Княжеская власть не брала на себя обязанность преследования преступников, выполняя лишь непосредственно функцию правосудия. Поиск совершившего преступление и доказывание его вины были делом пострадавшего или ближайшего заинтересованного в этом лица $[4$, с. 30]. Потерпевший имел право сам начать «гонение следа», т. е. разыскивать преступника по следам $[3$, c. 20]. Поэтому при обнаружении разыскиваемого потерпевший сам выступал инициатором и ис-полнителем задержания (ст. ст. 113, 114 Русской Правды).

Проанализировав нормы Русской Правды, Н.В. Попков пришел к выводу, что этим документом регулировалось задержание подозреваемого в совершении преступления и задержание разыскиваемого лица. Основанием для последнего, согласно ст. ст. 113, 114 Русской Правды Пространной редакций и ст. 46 Сокращенной редакции, являлось непосредственное обнаружение разыскиваемого холопа. Это основание, по мнению автора, по своей природе идентично основанию при задержании разыскиваемого обвиняемого, установленного ч. 3 ст. 210 УПК [5, с. 19]. Однако с подобным утверждением трудно согласиться, потому что отождествление оснований рассматриваемых мер принуждения происходит лишь по некоторым внешним признакам: в обоих случаях лицо скрывается, ограничивается свобода передвижения. Вместе с тем в рассматриваемых ситуациях различны по сути причины лишения лица свободы. Совершение холопом побега по Русской Правде было само по себе преступлением. Поскольку скрывшийся «челядин» правами не обладал (он выступал объектом права), то с момента побега он становился виновным. Цель задержания заключалась в том, чтобы доставить сбежавшего холопа к своему хозяину, который по своему усмотрению назначал ему наказание. Соответственно, данный вид задержания был обусловлен потребностью исполнения наказания. В результате задержания каких-либо материально-правовых последствий для обвиняемого не наступает. Основания задержания, содержащиеся в Русской Правде, принципиально отличаются от положений УПК. Древнерусская мера принуждения, скорее, похожа на задержание осужденного, производимое в соответствии с Уголовноисполнительным кодексом.

Таким образом, уже в первых источниках права описываются отдельные стороны принуждения, направленного на доставление преследуемых лиц в необходимое место. Анализ норм Русской Правды позволяет проследить, как формировался институт задержания [6, с. 9-10]. Эта мера принуждения характеризовалась краткосрочностью и тем, что она изначально носила подчиненный характер: задержание было необходимо для доставления на княжеский двор, где отправлялось правосудие. Задержание допускалось и в целях выяснения обстоятельств совершения преступления, и в целях исполнения назначенного наказания. Оно процессуально не оформлялось, его сроки не указывались. Особенностью этого этапа являлась достаточно высокая роль частного правового принуждения, что обусловливалось неразвитостью государственного аппарата и, как следствие, невысоким уровнем участия государства в регулировании общественных отношений.

На втором этапе (XV-XVI вв.) уголовный процесс стал приобретать публичный характер. Из многочисленных правовых документов того времени наибольшее значение имели Судебники 1497 г. и 1550 г. Усиление государственного начала способствовало дальнейшему формированию системы мер принуждения. Определилась и новая мера принуждения в отношении преследуемого лица - «отдача за пристава», которая состояла в лишении свободы 
человека. Государственных тюрем еще не было, поэтому арестованных содержали во дворе у пристава, обязанного наблюдать за ними. Позднее «отданные за пристава» содержались в помещении того приказа, в котором рассматривалось дело.

Заметим, что в период действия Русской Правды, как, впрочем, и гораздо позже, вплоть до конца 19 в., отсутствовало разграничение между подозреваемым и обвиняемым. Соответственно, задержание применялось независимо как от наличия указанных статусов, так и от этапа расследования.

В законодательных памятниках этого периода можно встретить упоминания о таком способе доставления к месту расследования, как задержание. В отличие от предыдущего этапа, задержание стало применяться в интересах не только частного лица, но и государства. Постепенно назначались специально уполномоченные на отыскание и поимку преступников должностные лица. Доставление задержанных осуществлялось на основании принятого и оформленного соответствующим образом документа.

Так, в случае необходимости доставления заподозренного лица в суд, в том числе из другого города, согласно ст. 28 Судебника 1497 г., судья писал приставную грамоту, предоставляющую возможность приставу доставить лицо [7, с. 343]. При этом, по усмотрению судьи, пристав мог отдать ответчика на поруки или, при необходимости, содержать его под арестом. Приставу полагалось вознаграждение за поездку по поручению суда. Закон запрещал приставам выезжать на место, если сумма иска была меньше вознаграждения, причитающегося за поездку. Приставу, направленному в другой город, необходимо было предъявить приставную грамоту непосредственно наместнику. Самостоятельно действовать на территории наместничества без санкции наместника пристав не имел права [7, с. 393]. Князья, охраняя независимость своего суда, в договорных грамотах старались оберегать свои уделы от въезда пристава другого князя. Исключением были царские приставы, которые могли доставить преследуемое лицо из любого удела. Редко, но выдавались жалованные грамоты отдельным лицам на «приставство в отчинах» какого-либо монастыря [8, с. 15-16]. Таким образом, на данном этапе складываются предпосылки для формирования такого условия правомерности мер принуждения, в том числе задержания, как осуществление их соответствующим субъектом.

Некоторые правила, касающиеся отдельных сторон задержания и доставления лица к месту расследования, изложены в Соборном Уложении 1649 г. (далее - Уложение). Данный законодательный акт представляет собой третий этап развития системы мер процессуального принуждения.

В Уложении перечислялись меры, направленные на обеспечение участия в суде уклоняющегося ответчика. Если он скрывался и не давал «поручной записи», то в соответствии со ст. 119 главы 10 Уложения ответчика разыскивали. Обнаруженного доставляли к судье, который его задерживал до представления им поручителей [9, с. 41].

Если ответчик не выполнял требования, содержащиеся в «поручной записи», и скрывался, то пристав осуществлял его розыск (ст. 138 главы 10 Уложения). Разысканный ответчик доставлялся в суд, где платил истцу за «волокиту», а «недельщику» за расходы, связанные с его доставлением к месту рассмотрения дела [10, с. 151]. Если ответчик, отпущенный на поруки, вновь скрывался, то он подвергался тюремному заключению на три месяца (глава 10 ст. 142 Уложения).

Анализ предназначения указанных мер принуждения позволяет утверждать, что на этом этапе развития отечественного права произошло разграничение по целевому признаку между такими мерами принуждения, как задержание и арест. Если ответчик находил поручителей, то последующая потребность в содержании его под стражей отпадала. Тогда речь ведется о краткосрочном лишении свободы - задержании. Задержание скрывающегося ответчика, не желающего давать «поручную запись» до представления им поручителей или нарушившего её предписания, имеет некоторые общие черты с современным задержанием обвиняемого. В частности, в обоих случаях меры принуждения применяются в отношении разыскиваемого лица. Кроме того, они направлены на выяснение обстоятельств уклонения и решения вопроса об избрании долгосрочной меры принуждения, т. е. имеют вспомогательный характер.

Арест был мерой принуждения с целью изоляции лица и обеспечения возможности должностным лицам совершить с ним определённые действия, требующие продолжительного времени. Арест применялся в тех случаях, когда ответчик не находил себе поручителей, а также если ответчик нарушал условия «поручной записи».

В первой половине XVII в. тюремное заключение стало весьма распространенной мерой предупреждения [8, с. 41]. Правом на взятие под стражу и на привод обвиняемых обладали не только должностные, но и частные лица. Принудительно доставленных в приказ или тюрьму принимали дьяки и подьячие. При заключении под стражу иногда соблюдались некоторые формальности. Так, для привода «оговоренных» людей давались «наказные памяти», на основании которых можно было 
доставлять обвиняемых в приказы. Об исполнении возложенного на них поручения уполномоченные лица составляли «доездные памяти». На них дьяк или подьячий, принявший задержанное лицо, делал надпись: «А приводного принять и расспросить».

Таким образом, в XVII в. решение об ограничении свободы стало процессуально оформляться, причем составлялись два документа: один - лицом, правомочным принять решение о мере принуждения; второй - непосредственно лицом, исполняющим принятое решение о доставлении.

Дальнейшее усиление государственного начала в уголовном процессе и ликвидация остатков раннего обвинительного судопроизводства продолжились при Петре I. Была отменена «отдача за пристава». Основной мерой принуждения становится содержание под стражей в тюрьме [11, с. 16].

Следующим шагом в развитии отечественной системы мер процессуального принуждения следует считать вступивший в силу 1 января 1835 г. Свод законов Российской империи, который заменил Уложение Алексея Михайловича и все последующее некодифицированное законодательство. По сравнению с Уложением 1649 г., Свод законов являлся более систематизированным сборником. Законы, относящиеся к различным отраслям права, были выделены в особые тома Свода. Пятнадцатый том назывался «Свод законов уголовных», а вторая его книга «О судопроизводстве по преступлениям» [12, c. 735]. Учитывая, что следственная форма процесса требовала личного присутствия обвиняемого во время следствия и суда, авторы Свода законов предусмотрели меры, направленные на розыск и доставление скрывающегося обвиняемого.

Известный юрист XIX в. Я.И. Баршев выделял две группы мер, направленных на обнаружение и доставление скрывающегося обвиняемого в суд. Первая группа применялась в том случае, когда имелись сведения о вероятностном местонахождении уклоняющегося обвиняемого. В числе этих мер автор выделял: преследование обвиняемого; «сношение» с управлениями, в ведомстве которого скрывается обвиняемый. Вторая группа применялась в отношении скрывшихся обвиняемых, сведения о местонахождении которых отсутствовали:. Здесь можно было прибегнуть к публичному объявлению об обвиняемом, контактированию со всеми другими управлениями, описи имущества, «обнадеживанию» обвиняемого в случае его добровольной явки [13, с. 62-66].

Лица, которым поручалось преследование обвиняемого, обязаны были действовать и на территории другого уезда или губернии до тех пор, пока местная полиция не продолжит преследование скрывающегося лица. Пойманные в другом уезде или губернии обвиняемые сдавались местному начальству под расписку. При обнаружении обвиняемого в другом подсудном ведомстве для этапирования его к месту расследования надлежало информировать начальство того ведомства. Оно, в свою очередь, давало распоряжение своим подчиненным о доставлении разысканного лица к месту расследования [14, с. 121]. Разысканное лицо на время решения вопроса о его доставлении и этапировании содержалось под стражей. После его прибытия к месту расследования судья распоряжался по поводу возможности отдачи доставленного на поруки.

Нельзя не согласиться, что подобная процедура напоминает краткосрочное лишение свободы обвиняемого на время его доставления к месту расследования (задержание обвиняемого).

\section{Conclusion}

Безусловно, с изданием Свода законов меры пресечения были упорядочены. Вместе с тем их правовое регулирование содержало существенные недостатки: не ограничивалось количество лиц, правомочных их применять; отсутствовало требование о необходимости процессуального оформления применения мер пресечения; на содержание под стражей смотрели не только как на меру пресечения, но и как на средство (метод) раскрытия преступления. При таком порядке каждый, «повлекший на себя подозрения полиции», мог быть по их усмотрению взят под стражу и содержаться в тюрьме три дня без необходимых на то специальных оснований. Если задержанному в течение трех дней объявлялись причины взятия под стражу или его допрашивали, то он содержался под стражей до окончания следствия. В Своде законов полагалась ответственность за взятие кого-либо под стражу без веских на то оснований. Однако в законе о судопроизводстве не указывались основания, при наличии которых следователь был вправе взять подозреваемого под стражу. По этой причине данная норма на практике почти не применялась. Поскольку возможность ограничения свободы зависела от усмотрения должностного лица, постольку вопросы правомерности доставления разыскиваемого к месту расследования не вызывали ни в обществе, ни в правоохранительных органах острого неприятия. Факт продолжительного ограничения свободы (время доставления разысканного обвиняемого к месту расследования) воспринимался как само собой разумеющийся. 


\begin{tabular}{l|lr|ll|ll} 
& ISRA (India) & $=\mathbf{1 . 3 4 4}$ & SIS (USA) & $=\mathbf{0 . 9 1 2}$ & ICV (Poland) & $=\mathbf{6 . 6 3 0}$ \\
Impact Factor: & ISI (Dubai, UAE) $=\mathbf{0 . 8 2 9}$ & PUHЦ (Russia) $=\mathbf{0 . 2 0 7}$ & PIF (India) & $=\mathbf{1 . 9 4 0}$ \\
& GIF (Australia) & $\mathbf{0 . 5 6 4}$ & ESJI (KZ) & $=\mathbf{4 . 1 0 2}$ & IBI (India) & $=\mathbf{4 . 2 6 0}$ \\
& JIF & $=\mathbf{1 . 5 0 0}$ & SJIF (Morocco) & $=\mathbf{2 . 0 3 1}$ & & \\
\hline
\end{tabular}

\section{References:}

1. Lyublinskiy P. I. (1926) Meryi presecheniya. 3-e izd., dop. - M., 1926. - p. 3.

2. Foynitskiy I.Ya. (1996) Kurs ugolovnogo protsessa. - SPb., 1996. - T. 2. - p. 323-324.

3. (1997) Russkaya Pravda // Hrestomatiya po istorii gosudarstva i prava / pod red. Yu.P. Titova. - M, 1997.

4. Pogoretskiy N.A. (2004) Russkaya Pravda o poiske prestupnikov i dokazyivaniya ih vinyi // Istoriya gosudarstva i prava. - 2004. - \# 3. - p. 30.

5. Popkov N.V. (2007) Zaderzhanie podozrevaemogo i obvinyaemogo kak vid gosudarstvennogo prinuzhdeniya: dis. ... kand. yurid. nauk. - N.Novgorod, 2007. - p. 19.

6. Demidov P.V. (2006) Chastnoe pravovoe prinuzhdenie: istoricheskaya retrospektiva // Istoriya gosudarstva i prava. - 2006. - \# 2. - p. 9-10.

7. (1955) Pamyatniki russkogo prava / pod red. L.V. Cherepnina. - M., 1955. - Vyip. 3. - p. 343.
8. Kistyakovskiy A. (1868) O presechenii obvinyaemomu sposobov ukloneniya ot sledstviya i suda.-SPb., 1868. - p. 15-16.

9. Man'kov A.G. (1987) Sobornoe Ulozhenie 1649 g. Tekst. Kommentarii. - L.: Nauka, 1987.-p. 41.

10. (1999) Otechestvennoe zakonodatelstvo XI-XX vv. / pod red. O.I. Chistyakova. -M.: Yurist, 1999.-Ch. 1. - p. 151

11. Kutuev E.K., Mustafaeva N.M. (2007) Razvitie instituta prinuzhdeniya $\mathrm{v}$ ugolovnom protsesse v XVIII v. pervoy polovine XIX v. // Istoriya gosudarstva i prava. - 2007. - \# 10. - p. 16.

12. Cheltsov-Bebutov M.A. (1957) Kurs sovetskogo ugolovno-protsessualnogo prava. M., 1957.-T. 1. - p. 735.

13. Barshev Ya.I. (2001) Osnovyi ugolovnogo sudoproizvodstva s primeneniem k ugolovnomu sudoproizvodstvu. - M., 2001. - p. 62-66.

14. Linovskiy V.A. (2001) Opyit istoricheskih razyiskaniy o sledstvennom ugolovnom sudoproizvodstve v Rossii. - M., 2001. - p. 121. 